\title{
Gossipiboma: Kaybolan Spançların İki Farklı Öyküsü
}

\author{
Gossypiboma: Two Different Stories of Lost Sponges
}

\section{Behiç Akyüz}

Kestel Devlet Hastanesi, Radyoloji Birimi, Bursa / Türkiye

\section{Yazışma Adresi / Correspondence:}

Behiç Akyüz

Kestel Devlet Hastanesi, Radyoloji Birimi, Kestel/Bursa

T: +905548453169 E-mail: behicakyuz@gmail.com

Geliş Tarihi / Received : 12.07.2019 Kabul Tarihi / Accepted : 11.12.2019

Orcid:

Behiç Akyüz https://orcid.org/0000-0002-3797-8147

( Sakarya Tip Dergisi / Sakarya Med J 2019, 9(4):733-737) DOI: 10.31832/smj.591302

\footnotetext{
Öz

Gossipiboma, operasyon lojunda unutulmuş cerrahi spançlar nedeniyle oluşmuş kitle lezyonlardır. Unutulmuş cerrahi materyaller nadir ve önemli bir komplikasyondur. Nadir görülmesi ve semptomlarının spesifik olmaması nedeniyle tanısı klinik olarak zordur. Operasyon öyküsü bulunan olgularda gossipiboma olasilığı her zaman akılda tutulmalıdır. Bu sunumda, histerektomi ve lomber disk cerrahisi sonrası, spesifik olmayan ağrı ve ateş şikayetleri ile başvuran, iki farklı olguyu ele alıyoruz.

Anahtar gossipiboma; cerrahi komplikasyonlar; yabancı cisim

kelimeler
}

Abstract

Gossipiboma is a mass lesion formed in the operation region due to forgotten surgical sponges. Forgotten surgical materials are rare and an important complication. The diagnosis is clinically difficult because it is rare and its symptoms are not specific. The possibility of gossipiboma should always be kept in mind in cases with a history of operation. In this report, we present two different cases who presented with non-specific pain and fever complaints after hysterectomy and lumbar disc surgery.

Keywords gossypiboma; surgical complications; foreign body 


\section{GIIRIș}

Latince gossypium (pamuk) ve boma (gizlenen) kelimelerinden kaynaklanan gossipiboma, cerrahi operasyonlar s1rasında vücut içinde unutulmuş cerrahi spanç ve çevresindeki yabancı cisim reaksiyonunu tanımlar. ${ }^{1,2}$ Unutulmuş cerrahi spanç nadir ancak önemli bir komplikasyondur. ${ }^{3}$ Klinik tablo, asemptomatik vakalardan ölümcül vakalara kadar değişebilmektedir. Bilgisayarlı Tomografi (BT) başta olmak üzere radyolojik görüntüleme yöntemleri gossipibomaların tanısında çok değerlidir. Bu sunumda, histerektomi ve lomber disk cerrahisi sonrası spesifik olmayan ağrı ve ateş şikayetleri ile başvuran iki farklı olguyu ele alıyoruz.

\section{OLGU SUNUMU}

64 yaşında, geçmişinde lomber disk cerrahisi öyküsü bulunan erkek hasta, sürekli ateş, devam eden bel ağrısı yakınmasıyla ile kliniğimize başvurdu. Enfeksiyon şüphesiyle elde olunan lomber manyetik rezonans (MR) incelemesinde, L5-S1 diskine komşu end platelerde ve diskte ödematöz sinyal değişiklikleri izlendi. Bu düzeyde sağda laminektomi defekti ve defekt boyunca sağ paravertebral mesafeden lateral reses boyunca diske uzanım gösteren, yaklaşık 77x33 mm boyutlarında, T1 ağırlıklı sekanslarda hipointens, T2 ağırlıklı STIR heterojen hiperintens, intravenöz kontrast madde (İVKM) sonrası periferal kontrastlanma gösteren, apseiform koleksiyon alanı izlendi (Resim
1). BT 'de merkezinde gaz kabarcıkları bulunan kitle imajı şeklinde izlendi (Resim2). Kitle cerrahi olarak görüldü ve çıkarıldı. Histopatolojik inceleme sonucunda süngeri çevreleyen yabancı cisim granülomu şeklinde raporlandı.

Diğer olgu elli dört yaşında kadın hasta, acil servise nonspesifik karın ağrısı, ateş ve halsizlik şikâyeti ile başvurdu. 6 ay önce başka bir merkezde histerektomi operasyonu geçirdiğini belirten hastanın fizik muayenesinde sağ kadranda lokalize hassasiyet ve rebound, subfebril ateş ve laboratuar testlerinde lökositoz mevcuttu. Direkt batın grafisi ve bunu takiben kontrastsız batın BT tetkikleri yapıldı. Batın grafisinde, sağ kadranda yaklaşık 11x9 cm boyutlarında, içerisinde kıvrılmış lineer hiperdansite bulunan, düzgün sınırlı, oval, radyoopak görünüm mevcuttu. Sonrasında çekilen kontrastsız batın BT incelemede, içerisinde yabancı cisime ait kıvrılmış lineer hiperdansiteler gözlenen, 115 x90 mm boyutlu, duvar yapısı bulunan, içerisinde yaygın hava imajları içeren, büyük oranda hipodens, düzgün konturlu, yer kaplayan lezyon izlendi (Resim 2). Mevcut klinik ve radyolojik bulgularla hasta gossipiboma ön tan1sı ile cerrahi operasyona alındı. Cerrahi sonrası dokunun histopatolojik değerlendirilmesinde yabancı cisim reaksiyonu, fokal fibrozis ve apse ile uyumlu bulunarak gossipiboma tanısını doğrulandı.

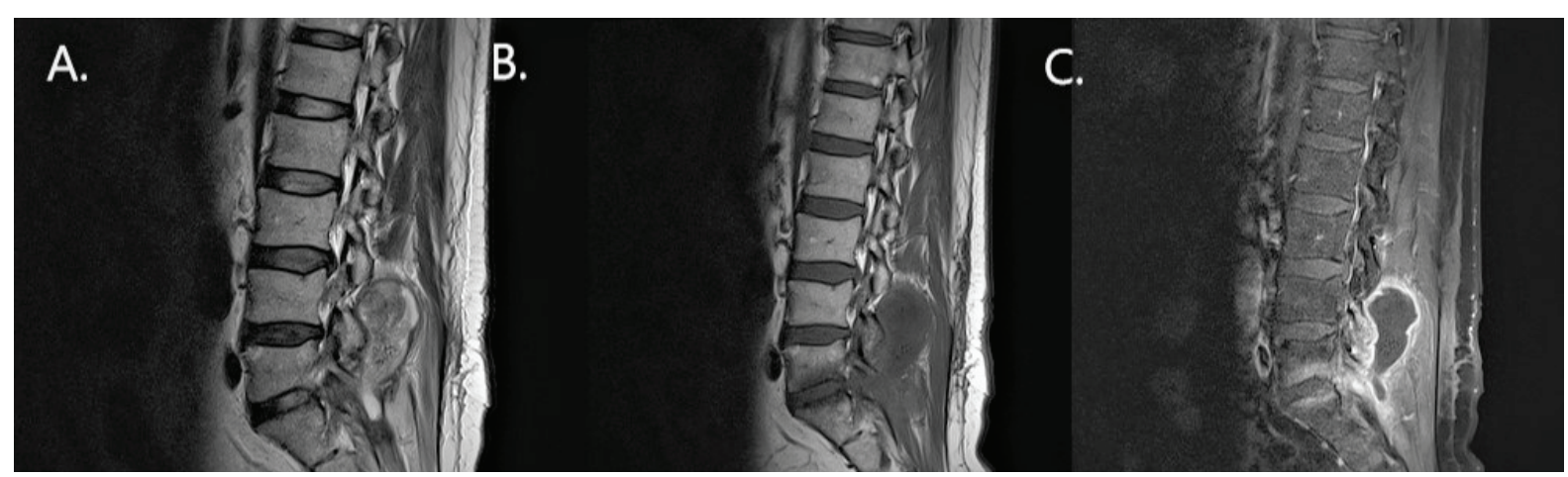

Resim 1. Elli dört yaşında kadın hastada, lomber gossipiboma MR görüntüleri. A. T2 ă̆ırlıkl sekans heterojen hiperintens B. T1 ağırlıklı sekanslarda hipointens C. Yă̆ baskılı T1 ağırlıklı sagital görüntüler intravenöz gadolinyum sonrası periferal kontrastlanma gösteren kolleksiyon alanı. Lezyon içerisinde T1 ve T2 ă̆ırlıklı imajlarda hava değerlerine ait olabilecek noktasal signal void odaklar da mevcut. 


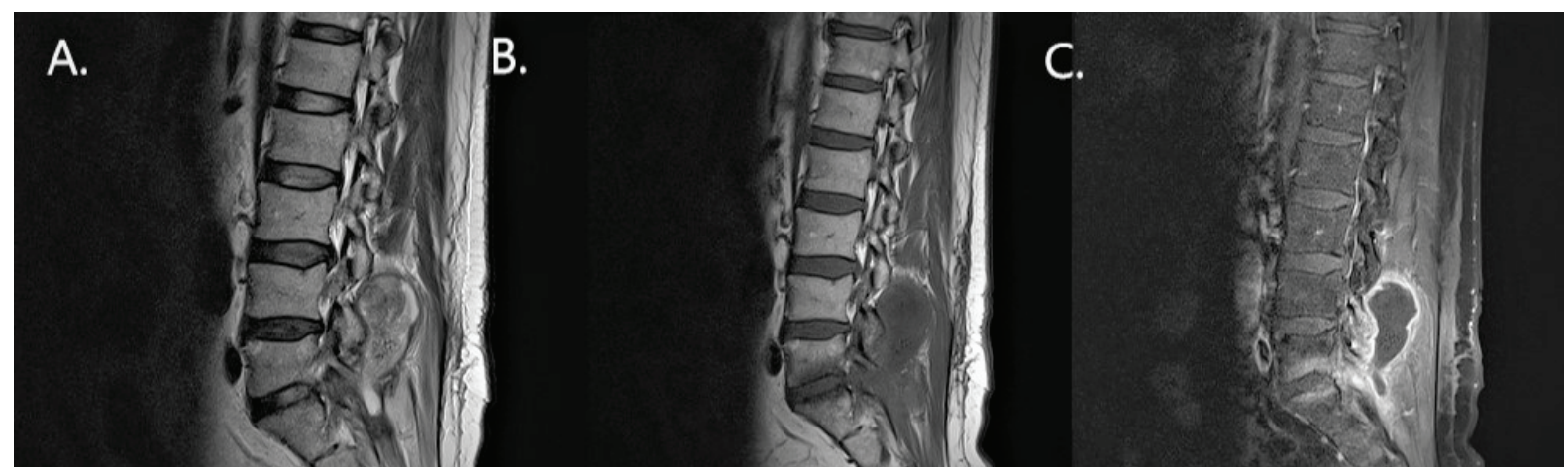

Resim 2. Lomber gossipiboma olgusu. A. Kontrastsız lomber BT aksiyel görüntüsü. Ok ile gösterilen içerisinde hipodens hava değerleri gözlenen hipodens kitle imajı B. Yağ baskılı T1 ağırlıklı aksiyal görüntüler İV gadolinyum sonrası periferal kontrastlanma gösteren kolleksiyon alani.

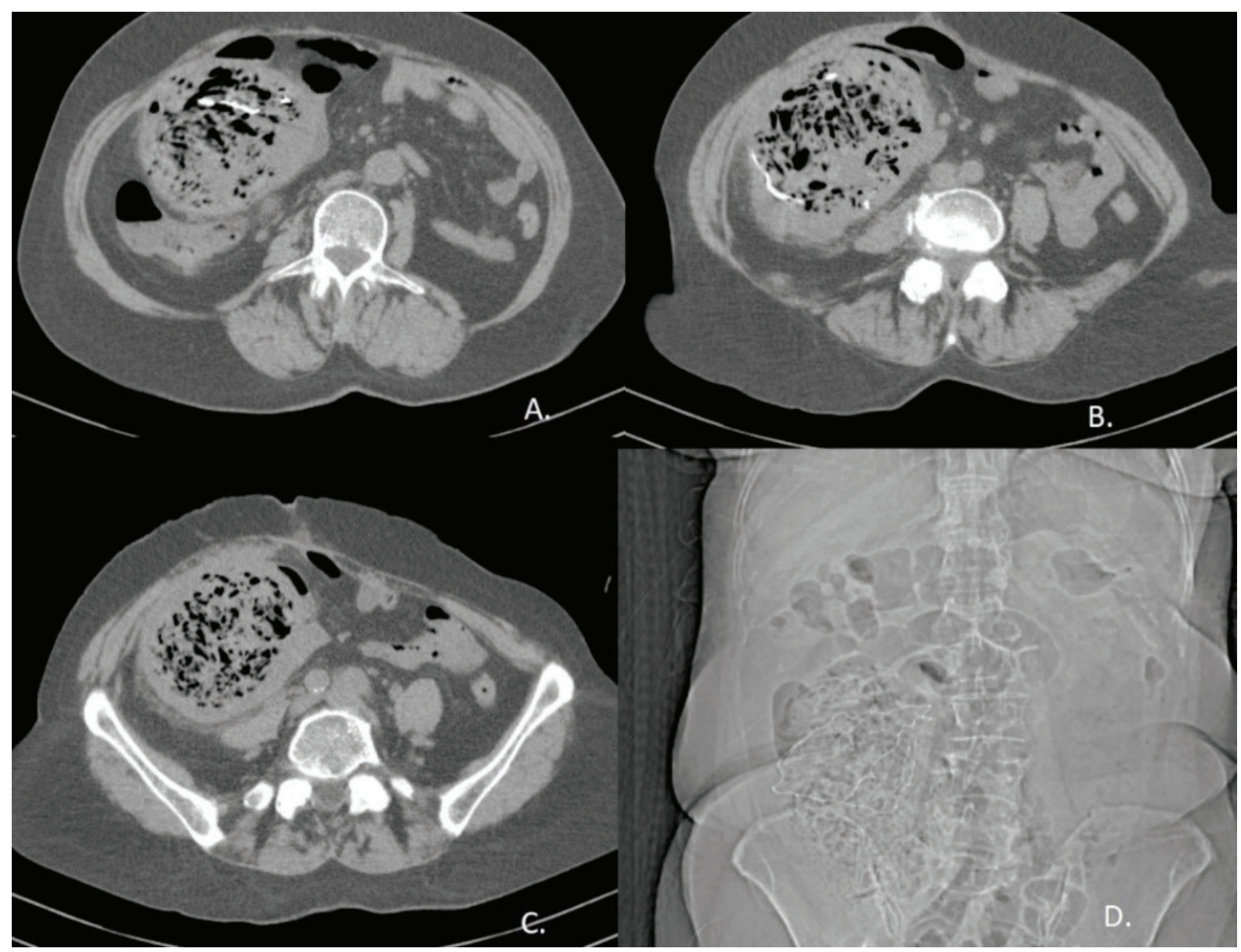

Resim 3. Elli dört yaşında kadın hastada, intraabdomial gossipiboma olgusu. A.B.C. Kontrastsız aksiyel batın BT görüntülemede batın să̆ alt kadranda, intestinal anslara komşu $115 \times 90 \mathrm{~mm}$ boyutlarında, içerisinde yaygın hava imajları içeren büyük oranda hipodens yer kaplayan lezyon. D. BT öncesi alınan skenogramda içerisinde kıvrılmış lineer opasite ve hava imajları bulunan spongiform radyoopak görünüm 


\section{TARTIŞMA}

Gossipiboma, operasyon bölgesinde, unutulmuş cerrahi materyaller nedeniyle oluşmuş kitle lezyonlardır. İlk gossibipoma 1884 yılında laparotomi sonrası karın içi tekstil varlığını gözlemleyen Wilson tarafından tarif edilmiştir. Medikolegal nedenlerden dolayı vakaların gerçek sıklığ1 tam olarak bilinmemektedir. ${ }^{4}$ Morbid obez hastalarda, bilimsel ilerlemelerden dolayı daha invaziv cerrahi prosedürler ve multidisipliner operatif yaklaşımlar gossipiboma riskini artıran faktörlerdir. ${ }^{10}$ Unutulan materyaller iki farklı tipte reaksiyon oluşturabilir. Birincisi granülasyonla sonuçlanan aseptik fibrinöz yanıt ve sonrasında gelişen fibröz kitle varlığı; ikincisi kist ve apse formasyonuna neden olan eksudatif reaksiyondur. ${ }^{5,6}$ Batın içi gossipibomalar periton boşluğundan gastrointestinal sisteme veya mesaneye ekstrude, cilde ve barsaklara fistülize olabilir, barsak obstrüksiyonu ve perforasyonu gelişebilir. ${ }^{7}$ Ayrıca bizim vakalarımızda olduğu gibi ileusla sonuçlanabilen barsak yapışıklıkları veya abseiform koleksiyon ile sonuçlanabilir.

Gossibipoma teşhisi, semptomların spesifik olmayışı veya yokluğundan dolayı klinisyen ve radyolog için zor olabilir. Direk grafi özellikle eğer materyal radyoopak işaretleyicileri içeriyorsa ilk değerlendirmede faydalıdır. Ancak bunları kalsifikasyon, kontrast maddr, cerrahi klipslerden ayırmak önemlidir. ${ }^{1,2}$ BT, gossibipoma ve komplikasyonlarının teşhisinde altın standart yöntem olarak kabul edilir. Tomografide içinde gaz içerebilen ve kontrast sonrası yüksek bir yoğunluğa sahip olan, heterojen içerikte, süngerimsi, değişken yoğunluklu iyi tanımlanmış kitle şeklindedir. Duvar kalsifikasyonlarının yanı sıra, malzemenin işaretleyicilerine ait sarmal veya kıvrımlı hiperdens çizgiler seçilebilir. Gossipiboma kontrast madde verilmesini takiben kontrast tutan ince veya kalın kapsüllü düşük dansiteli kitlesel lezyon şeklinde izlenebilir. Bu görünüm apse ve hematom ile karışabilir. ${ }^{2}$ Absorbe olabilen hemostatik bezlerin de akılda tutulması gerekmekte olup fokal santral hava imajı içeren miks-düşük atenuasyonlu kitleler şeklinde göründükleri hatırlanmalıdır. Absorbe olabilen hemosta- tik tıkaçlar cerrahi gazlı bezlerden farklı olarak radyoopak işaret içermemektedir. Ayrıca absorbe olabilen tıkaçların takipte görüntülerden kaybolduğu da izlenecektir. ${ }^{1}$ Diğer radyolojik görüntüleme yöntemleri olan ultrason ve MR gossipiboma tanısında değerli bilgiler verebilir. Ultrasonda operasyon öyküsü bulunan hastada güçlü posterior akustik gölgelenme oluşturan hiperekojen kıvrımlı yapılar içeren, kitle imajı yabancı cismi akla getirmelidir. MR'de gossibipoma genellikle kitle bileşenine veya komplikasyonların varlığına göre değişken sinyal yoğunluğuna sahip, iyi sınırlı bir kapsül ile çevrili heterojen bir kitle olarak ortaya çıkar. Yabancı cisim içinde bulunabilen radyoopak işaretleyicinin manyetik ve paramanyetik etkilerinden dolayı tanıda güçlüklere neden olabilmektedir. Ancak genel olarak T1 ağırlıklı görüntülerde yabancı cisme ve içinde hapsolmuş hava ve sıvı içeriğine bağlı büyük oranda heterojen hipointens, T2 ağırlıklı görüntülerde yabancı cisim ve hava imajlarına bağlı hipointens, sıvı içeriğine bağlı olarak hiperintens alanlar içeren heterojen intensitede lezyon olarak izlenir. Ayrıca IV gadolinyum enjeksiyonu sonrası T1 ağırlıklı görüntülerde kontrast tutan kapsül görüntülenebilir. ${ }^{8}$ Kesin tanı yabancı cismin ve buna bağlı reaksiyonların histopatolojik tanısı ve cerrahi materyalin görülmesi ile konur.

Riski minimuma indirmek için cerrahi operasyonlarda kullanılan malzemelerin operasyon öncesi ve sonrası sayımı, radyolojik olarak tespit edilebilen malzemelerin kullanılması ve riskli operasyonlar sonunda radyolojik olarak muhtemel unutulan yabancı cisme yönelik radyolojik tarama önerilmektedir. Ayrıca teknolojideki yeni gelişmeler (elektronik çip, barkod sistemi gibi) ile de bu riskin azaltılabileceği umulmaktadır. ${ }^{9}$

Sonuç olarak, nadir görülmesi, bulguların spesifik olmaması nedeniyle tanısı klinik olarak zor olmakla birlikte operasyon öyküsü bulunan vakalarda gossipiboma olas1lığı da akılda tutulmalıdır. 
Sakarya Tip Dergisi 2019;9(4):733-737

BEHIÇ AKYÜZ, Gossipiboma: Kaybolan Spançların İki Farklı Öyküsü

\section{Kaynaklar}

1. Topal U, Şahin N, Gökalp G, Gebitekin C. İntratorasik tekstilomlarda radyolojik bulgular. Tanısal ve Girişimsel Radyoloji 2004;10:280-3

2. O'Connor AR, Coakley FV, Meng MV, Eberhardt S. Imaging of retained surgical sponges in the abdomen and pelvis. AJR 2003;180:481-9

3. Tim B. Hunter, Mihra S. Taljanovic medical devices of the abdomen and pelvis. RadioGraphics 2005;25(4):503-23

4. Gümüsstaş $O G$, Gümüşstaş A, Yalçın R, Savct G, Soylu RA. Unusual causes of small bowel obstruction and contemporary diagnostic algorithm. J Med Imag Rad Oncol 2008;52(2): 208-15

5. Lu Y, Cheung Y, Ko S, et al. Calcified reticulate rind sign: a characteristic feature of gossypiboma on computed tomography, a case report. World J Gastroenterol 2005;11(16):4927-9

6. Puvanesarajah, V., Fayad, L. M., Rao, S. S., McCarthy, E. F., \& Morris, C. D.. Extremity gossypiboma mimicking sarcoma: case report and review. Skeletal radiology 2019;48(4), 629-635.
7. Young ST, Paulson EK, McCann RL, Baker ME. Appearances of oxidized cellulose (surgicel) on postoperative CT scans: similarity to post-operative abscess. American Journal of Roentgenology 1993;160(2):275-7

8. Kim CK, Park BK, Hongil H. Gossypiboma in abdomen and pelvis: MRI findings in four patients. American Journal of Roentgenology 2007; 189(4): 814-817.

9. Fabian CE. Electronic tagging of surgical sponges to prevent their accidental retention. Surgery 2005; 137:298-301

10. Oehme, F., Rühle, A., Stickel, M., Metzger, J., \& Gass, J. M. The sucked surgical sponge: Rare case of Gossypiboma after vaginal hysterectomy. Clinical case reports 2019;7(4): 753 